\title{
EVALUASI SARANA PENDIDIKAN SEKOLAH DASAR KECAMATAN BATUNUNGGAL, KOTA BANDUNG
}

\author{
Ainurrahmi Novianti $1^{a}$, Tia Adelia Suryani $2^{b^{*}}$ \\ anstitut Teknologi Nasional (ITENAS); Jalan PHH Mustapha No 23, Kota Bandung \\ b Institut Teknologi Nasional (ITENAS); Jalan PHH Mustapha No 23, Kota Bandung; tiadelia@itenas.ac.id
}

Info Artikel:

- Artikel Masuk: 01/12/31
- Artikel diterima: 29/12/21

\begin{abstract}
ABSTRAK
Pendidikan anak usia sekolah dasar merupakan hal penting dalam tumbuh kembangnya. Suatu kota yang baik harus dapat menyediakan sarana Pendidikan yang layak. Salah satu kebijakan terbaru yang diterapkan oleh Pemerintah adalah system Zonasi. Kota Bandung terdiri dari 4 (empat) zonasi, yaitu Zona A, Zona B, Zona C, dan Zona D. Kecamatan Batununggal termasuk dalam Zona C. Semenjak adanya aturan zonasi sekolah, beberapa permasalahan mulai bermunculan. Evaluasi sarana Pendidikan sekolah dasar menjadi penting untuk diteliti agar dapat mengantisipasi permasalahan yang mungkin muncul di kemudian hari. Sarana Pendidikan SD di Kecamatan Batununggal dievaluasi berdasarkan jangkauan pelayanan dan aksesibilitasnya. Aksesibilitas yang dimaksud berupa kondisi fasilitas pejalan kaki, keberadaan zebra cross, dan rute angkutan umum yang ada di masing-masing sekolah. Metode yang digunakan adalah dengan analisis spasial buffering serta observasi kondisi eksisting Hasil penelitian menunjukkan seluruh SD yang ada di Kecamatan Batununggal sudah mampu melayani daerah sekitar bahkan hingga keluar Kecamatan. Terdapat 3 (tiga) SD yang memiliki fasilitas jalur pejalan kaki dan 3 (tiga) sekolah yang memiliki zebra cross sebagai sarana menyeberang jalan. Rute angkutan umum telah melayani semua zona pendidikan Sekolah Dasar (SD/MI) dengan 6 (enam) trayek yang tersedia di Kecamatan Batununggal, namun untuk zona sekolah yang berada di area permukiman, menjangkaunya harus berjalan kaki atau menggunakan kendaraan pribadi.
\end{abstract}

Kata Kunci : evaluasi, jangkauan, pelayanan, pendidikan, sarana

\section{ABSTRACT}

Elementary school age children's education is important in their growth and development. A good city must be able to provide proper educational facilities. One of the latest policies implemented by the Government is the zoning system. The city of Bandung consists of 4 (four) zoning, namely Zone A, Zone B, Zone C, and Zone D. Batununggal District is included in Zone $C$. Since the school zoning regulations, several problems began to emerge. Evaluation of primary school education facilities is important to research in order to anticipate problems that may arise in the future. Elementary education facilities in Batununggal sub-district were evaluated based on service coverage and accessibility. The accessibility in question is the condition of pedestrian facilities, the presence of a zebra cross, and public transportation routes in each school. The method used is spatial buffering analysis and observation of existing conditions. The results showed that all elementary schools in Batununggal District were able to serve the surrounding area even outside the District. There are 3 (three) elementary schools that have pedestrian facilities and 3 (three) schools that have a zebra crossing as a means of crossing the road. Public transport routes have served all elementary school education zones (SD/MI) with 6 (six) routes available in Batununggal District, but for school zones located in residential areas, reaching them must be on foot or using private vehicles.

Keyword: evaluation, outreach, service, education, facilities

\section{PENDAHULUAN}

Pengertian mengenai desa dan kota tidak akan lengkap apabila belum melihat seluruh system kehidupannya. Suatu system permukiman merupakan system kompleks yang terdiri atas 5 (lima) elemen meliputi alam, manusia, masyarakat, tempat tinggal (bangunan), dan jaringan (Doxiadis, 1970). Permukiman kota khususnya mencakup 5 (lima) komponen yang saling bergantungan, yaitu Wisma (tempat tinggal), Karya (tempat berkarya), Marga (jaringan jalan penghubung), Suka (tempat rekreasi), dan Penyempurna (prasarana utilitas dan pusat pelayanan kegiatan (Hadinoto, 1970 dalam Sujarto, 1992). Salah satu unsur penyempurna yang harus ada di Kawasan Permukiman kota adalah sarana Pendidikan.

Pendidikan sekolah meliputi jenjang Pendidikan dasar, menengah, dan tinggi. Pendidikan Nasional berfungsi mengembangkan potensi peserta didik agar 
menjadi manusia yang beriman dan bertakwa kepada Tuhan Yang Maha Esa, berakhlak mulia, berilmu, sehat, cakap, kreatif, mandiri dan menjadi warga negara yang demokratis dan bertanggung jawab (Undang- Undang Republik Indonesia Nomor 20 Tahun 2003 Pasal 12 Ayat 1 tentang Sistem Pendidikan Nasional, 2003). Mengingat fungsinya yang sangat penting maka pendidikan harus dapat dijangkau oleh seluruh masyarakat tanpa terkecuali. Pemenuhan pelayanan pendidikan mennjadi wajib dan menjadi tanggung jawab seluruh lapisan meliputi keluarga, masyarakat, pemerintah dan diharapkan sebarannya yang merata.

Zonasi adalah jalur penerimaan peserta didik berdasarkan pada radius atau jarak tempat tinggal calon peserta didik dengan Sekolah yang dituju dalam zona yang tertentu. Zonasi sekolah di Kota Bandung terdiri dari 4 (empat) zona: zona $A$, zona $B$, zona $C$, dan zona D. Apabila calon peserta didik berdomisili dalam radius 500 $\mathrm{m}$ ke sekolah tujuan namun berbeda zona maka dianggap satu zona dengan sekolah tersebut. Kuota jalur zonasi minimum $90 \%$ dari daya tampung sekolah (Peraturan Wali Kota Bandung Nomor 13 Tahun 2019 Tentang Tata Cara Penerimaan Peserta Didik Baru Pada Taman Kanak-Kanak, Sekolah Dasar, dan Sekolah Menengah Pertama, 2019).

Kecamatan Batununggal merupakan salah satu kecamatan di Kota Bandung dengan luas wilayah 52.600 ha dan memiliki kepadatan penduduk rata-rata $22.984 \mathrm{jiwa} / \mathrm{km}^{2}$. Kecamatan Batununggal terdiri dari 8 (delapan) kelurahan, yaitu Kelurahan Gumuruh, Kelurahan Binong, Kelurahan Kebon Gedang, Kelurahan Maleer, Kelurahan Cibangkong, Kelurahan Samoja, Kelurahan Kacapiring dan Kelurahan Kebon Waru. Secara administratif, batas Kecamatan Batununggal adalah sebagai berikut (Kecamatan Batununggal Dalam Angka 2020, 2020):

- Sebelah Utara : Kecamatan Bandung Wetan

- Sebelah Barat : Kecamatan Lengkong

- Sebelah Timur : Kecamatan Kiaracondong

- Sebelah Selatan : Kecamatan Bandung Kidul dan Kecamatan Buah Batu

Kecamatan Batununggal termasuk kedalam zonasi $\mathrm{C}$, untuk peserta didik berbeda zona namun masih dalam 1.000 m, maka dianggap masih dalam satu zona dan tetap dapat melakukan pendaftaran sekolah tersebut. Beberapa Sekolah Dasar yang terdapat di Kecamatan Batununggal antara lain: Sekolah Dasar Negeri 028 Gumuruh, Sekolah Dasar Negeri 145 Binong Jati, Sekolah Dasar Negeri 111 Pindad, dsb (Peraturan Wali Kota Bandung Nomor 13 Tahun 2019 Tentang Tata Cara Penerimaan Peserta Didik Baru Pada Taman Kanak-Kanak, Sekolah Dasar, dan Sekolah Menengah Pertama, 2019).

Semenjak aturan zonasi sekolah diterapkan, terdapat beberapa permasalahan yang terjadi. Tidak semua daerah bisa dijangkau oleh sekolah negeri terdekat, sementara beberapa sekolah sudah menutup pendaftarannya (Simbolon, 2018). Artinya, belum semua penduduk usia sekolah terjangkau oleh system zonasi. Oleh sebab itu penelitian ini bertujuan untuk mengevaluasi sarana Pendidikan Sekolah Dasar Kecamatan Batununggal, Kota Bandung.

\section{DATA DAN METODE}

Jenis penelitian ini merupakan penelitian deskriptif kuantitatif. Pengambilan sampel data dalam penelitian ini dilakukan dengan penentuan teknik non random sampling berdasarkan pemilihan suatu karakteristik atau ciri-ciri untuk mendapatkan sampel relevan untuk mencapai tujuan dari sebuah penelitian. Jenis teknik non random sampling yang dipilih yaitu purposive sampling. Purposive sampling adalah teknik pengambilan sampel sumber data dengan pertimbangan tertentu atau memiliki karakteristik tertentu. Pada penelitian ini untuk mendapatkan informasi mengenai objek penelitian yaitu jumlah peserta didik, rombongan belajar, luas ruangan dan luas lahan, dengan melakukan wawancara secara terstruktur, kepada pemilik informasi yaitu Kepala Sekolah atau Guru dari setiap Sekolah Dasar (SD/MI) di Kecamatan Batununggal. 


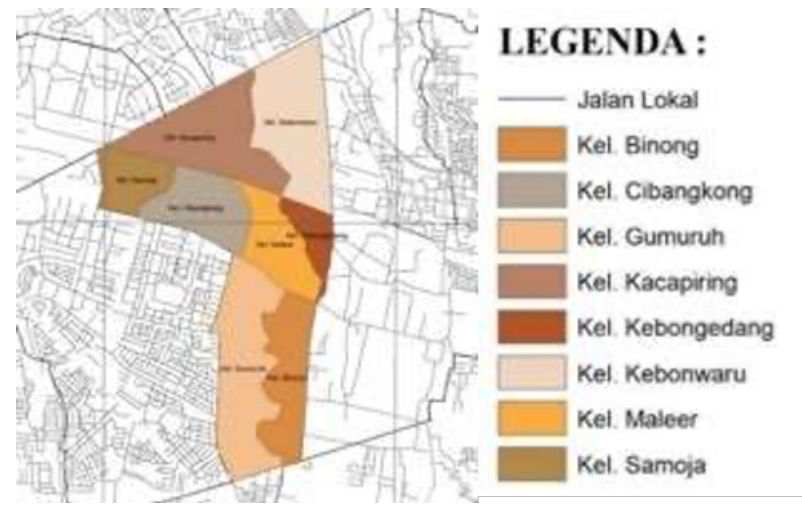

Gambar 1. Peta Wilayah Studi

\section{HASIL DAN PEMBAHASAN}

\subsection{Jangkauan Pelayanan}

Kecamatan Batununggal termasuk kedalam zona C yang terdiri dari Kecamatan Regol, Kecamatan Bandung Wetan, Kecamatan Batununggal, Kecamatan Bandung Kidul, Kecamatan Lengkong, dan Kecamatan Kiaracondong. Jangkauan pelayanan sarana Pendidikan Sekolah Dasar (SD/MI) yaitu 1000 m (Badan Standarisasi Nasional, 2004). Seluruh kelurahan yang ada di Kecamatan Batununggal sudah terjangkau oleh SD/MI yang ada. Artinya seluruh Kawasan yang berada di zona $\mathrm{C}$ sudah terlayani. Hal ini sudah sesuai dengan Standar yang ditetapkan oleh Pemerintah Indonesia. Jangkauan SD/MI di Kecamatan Batununggal bahkan sudah melayani kelurahan di luar Zona C. Untuk lebih jelasnya dapat dilihat pada Gambar 2.

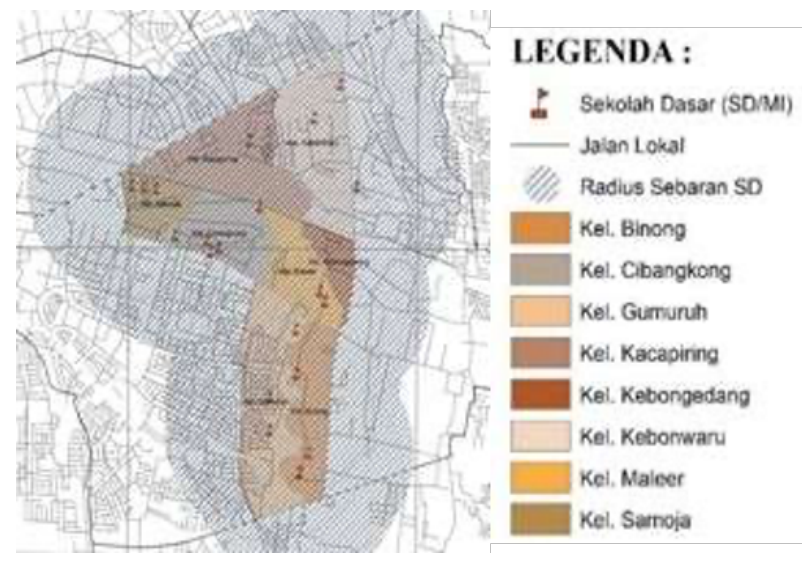

Gambar 2. Peta Jangkauan Pelayanan SD/MI

\subsection{Aksesibilitas Murid SD/MI}

Pada aspek sarana pendidikan Kota Bandung telah membentuk sekolah ramah anak, semua anak-anak usia bersekolah dan telah menyediakan infrastruktur seperti taman, ruang publik, dan rute aman dari dan ke sekolah (RASS). Fasilitas pejalan kaki dan fasilitas penyeberangan, merupakan konsep dari sekolah ramah anak. Fasilitas pejalan kaki dengan rute rumah ke sekolah harus dapat melayani 1000 m (Peraturan Menteri Perhubungan Republik Indonesia Nomor 16 Tahun 2016 Tentang Penerapan Rute Aman Selamat Sekolah (RASS), 2016).

Kecamatan Batununggal kondisi fasilitas pejalan kaki menuju area sekolah hanya terdapat di 3 (tiga) sekolah, namun fasilitas pejalan kaki yang tersedia hanya pada area depan sekolah saja, sehingga tidak melayani jarak 1000 m yaitu SDN 109 Centeh dilayani oleh jalan lokal yang terhubung jalan kolektor sekunder, SDN 203 Kacapiring dilayani oleh jalan kolektor sekunder dan SD Yayasan Beribu dilayani oleh jalan kolektor sekunder. Sebanyak 17 (tujuh belas) diantaranya tidak memiliki fasilitas pejalan kaki pada area depan sekolahnya sehingga kondisi sekolahnya langsung ke badan jalan dan dilayani oleh jalan lokal karena sekolahnya berada di lingkungan pemukiman.
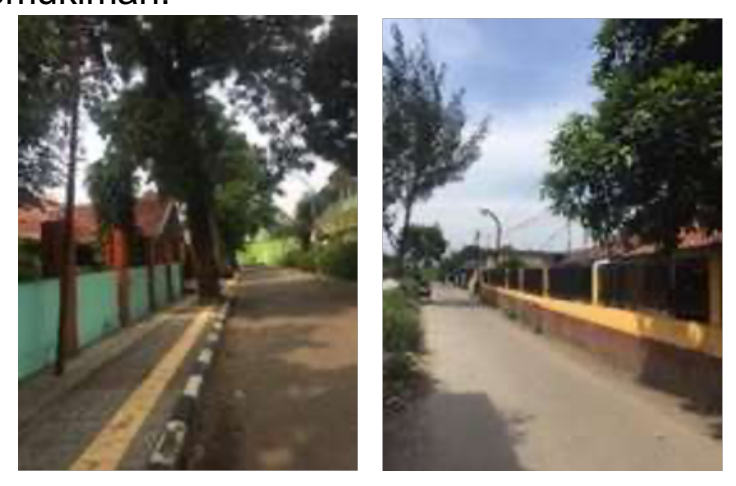

Gambar 3. (a) Sekolah terlayani trotoar (b) Sekolah tidak terlayani trotoar

Sementara itu, kondisi fasilitas penyeberangan hanya 3 (tiga) sekolah yang memiliki zebra cross, yaitu SD Yayasan Beribu (Kelurahan Kebon Gedang) berada di Jalan BKR dengan fungsi jalan kolektor sekunder, SD Ignatius Slamet Riyadi (Kelurahan Cibangkong) berada di Jalan Gatot Subroto dengan fungsi 
jalan kolektor sekunder dan SD Alfa Centauri (Kelurahan Samoja) berada di Jalan Teratai dengan fungsi jalan kolektor sekunder. Sebanyak 17 (tujuh belas) sekolah diantaranya berada pada area permukiman, dan tidak tersedia zebra cross.
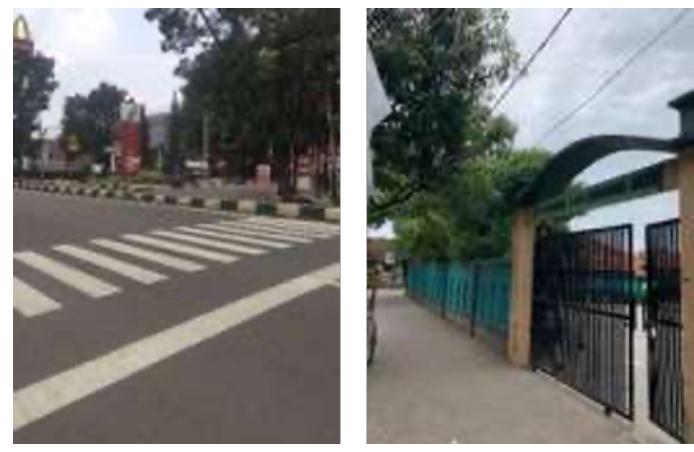

Gambar 4. (a). Sekolah yang tersedia Zebra Cross

(b). Sekolah yang tidak tersedia Zebra Cross

Kriteria pelayanan angkutan umum adalah rute dari rumah menuju ke sekolah dengan menggunakan angkutan umum dengan radius paling jauh $5 \mathrm{~km}$ dari lokasi sekolah dan jarak dari rumah ke tempat pemberhentian angkutan umum maksimal $1 \mathrm{~km}$ (Peraturan Menteri Perhubungan Republik Indonesia Nomor 16 Tahun 2016 Tentang Penerapan Rute Aman Selamat Sekolah (RASS), 2016). Kecamatan Batununggal dilayani oleh 6 trayek angkutan umum dengan rute sebagai berikut:

- Trayek 01 A, jurusan Kebon GedangCicaheum via Binong, melewati sekolahsekolah yang berada di Kelurahan Kebon Waru, Kelurahan Kebon Gedang, Kelurahan Maleer, Kelurahan Binong dan Kelurahan Gumuruh dengan rute yang dilalui Terminal Kebon Kelapa - JI Pungkur - JI Karapitan - JI Buah Batu - JI Banteng - JI Sancang - JI Lodaya - JI Martanegara - Jl Turangga - Jl Gatot Subroto - BSM - Binong - JI Kiara Condong - JI Jakarta - JI WR Supratman - JI Katamso - JI Pahlawan - Jl Cikutra JI PHH Mustofa (Suci) - Terminal Cicaheum.

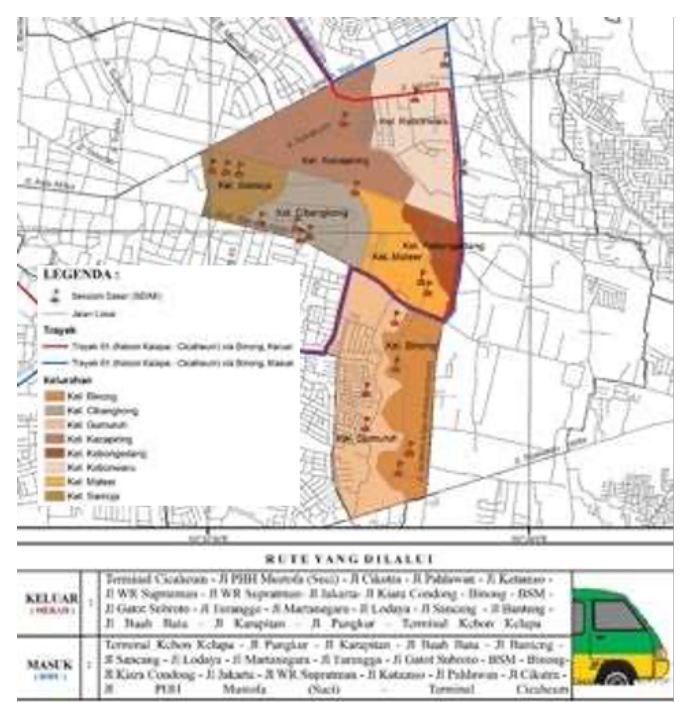

Gambar 5. Peta Trayek 01A

- Trayek 08, jurusan Cicaheum- Leuwi Panjang, melewati sekolah- sekolah yang berada di Kelurahan Kebon Waru, Kelurahan Kebon Gedang, Kelurahan Binong dan Kelurahan Gumuruh dengan rute yang dilalui Terminal Leuwi Panjang (Soekarno-Hatta)- JI Sukarno-Hatta - JI Kiara Condong - Jl Jakarta - Antapani Terminal Cicaheum.

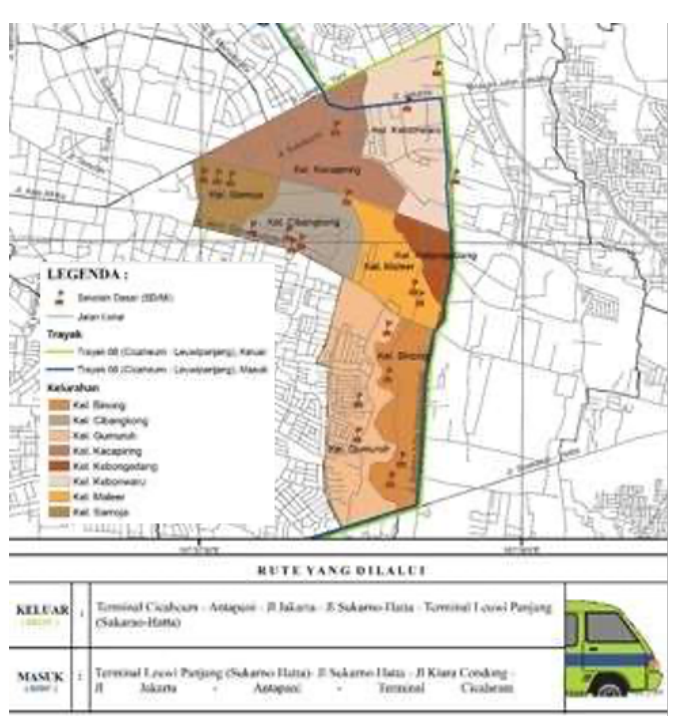

Gambar 6. Peta Trayek 08

- Trayek 14, jurusan Dago- Riung Bandung, melewati sekolah- sekolah yang berada di Kelurahan Kacipiring, Kelurahan Kebon Gedang, Kelurahan Binong dengan rute yang dilalui Terminal 
Dago - JI Ir H Juanda (Dago) - Simpang Dago - JI Dipati Ukur - JI Panatayuda - JI Surapati (Suci) - JI Sentot Alibasyah - JI Diponegoro - JI Citarum - JI RE Martadinata - JI Laswi - Jl Sukabumi - Jl Ahmad Yani - Jl Kiara Condong - JI Sukarno-Hatta - Margahayu Raya Metro - JI Cipamokolan (Riung Bandung) - JI Riung Bandung - Terminal Riung Bandung.

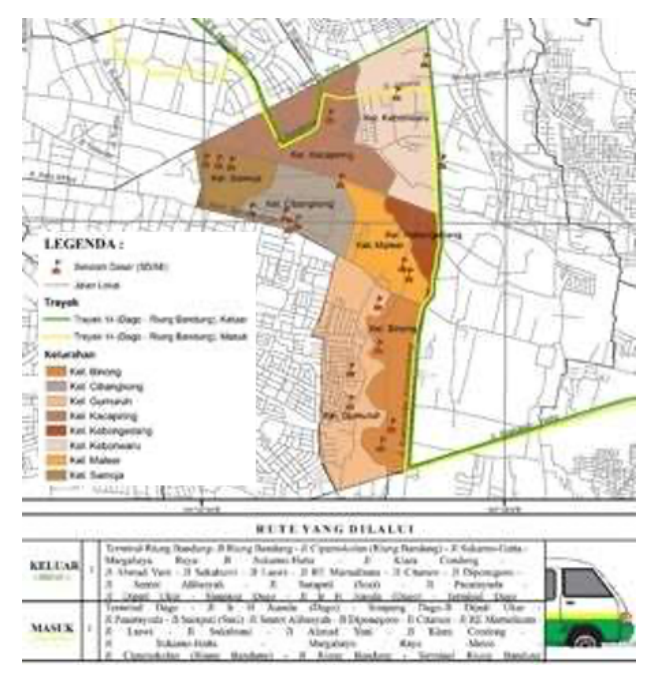

Gambar 7. Peta Trayek 14

- Trayek 15 Margahayu- Ledeng, melewati sekolah- sekolah yang berada di Kelurahan Kebon Waru, Kelurahan Kebon Gedang, Kelurahan Binong dengan rute yang dilalui Terminal Margahayu - Jl Rancabolang (Margahayu Raya) - JI Sukarno-Hatta - JI Kiara Condong - JI Jakarta - Jl. WR. Supratman - Jl. Cendana - JI Taman Pramuka - JI RE Martadinata - JI Merdeka - Jl Wastu Kencana - Jl. Pajajaran - Jl Cicendo - Jl Rivai - JI Cipaganti - JI Setiabudi - Jl Karang Sari JI Sukajadi - JI Setiabudi- Terminal Ledeng.

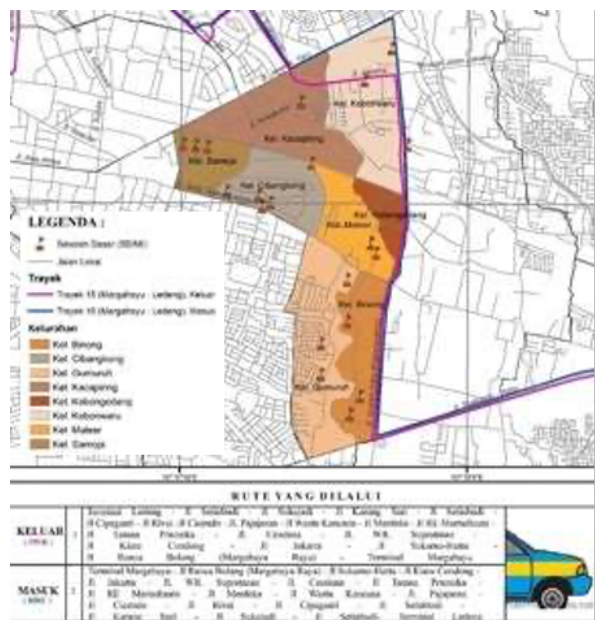

Gambar 8. Peta Trayek 15

- Trayek 16 Panghegar PermaiDipatiukur, melewati sekolah- sekolah yang berada di Kelurahan Kacapiring, Kelurahan Kebon Waru dan Kelurahan Samoja dengan rute yang dilalui Terminal Panghegar - JI Cisaranten - Jl Cicukang - JI AH Nasution (Raya Ujung Berung) - Sindanglaya - Terminal Cicaheum - Jl Ahmad Yani - Cicadas (Ahmad Yani) - Jl.KiaraCondong - Jl. Jakarta - JI Sukabumi - JI Laswi - JI RE Martadinata - Jl Ambon - Masjid Istiqamah - JI Cisanggarung - Jl Cimanuk - JI Cimandiri - JI. Cimalaya -J Diponegoro - JI Sulanjana - JI Tamansari - Jl Ganesha- ITB - RS Borromeus - JI. Hasanudin - JI Dipati Ukur -Terminal Dipati Ukur. 


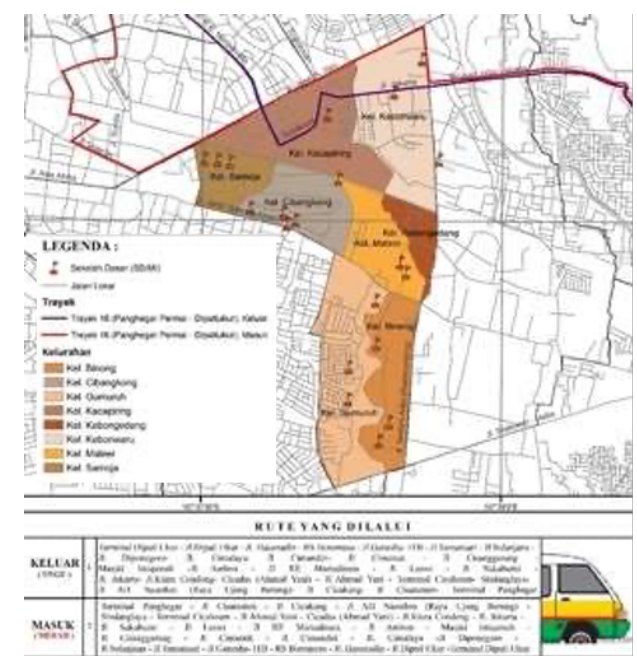

Gambar 9. Peta Trayek 16

- Trayek 23 Stasiun Hall- Gedebage, melewati sekolah- sekolah yang berada Kelurahan Samoja dan Kelurahan Gumuruh dengan rute yang dilalui Stasiun - JI Dulatip - Pasar Baru - JI Otto Iskandardinata (Otista)- Jl Kepatihan - JI Dewi Sartika - JI Dalem Kaum - AlunAlun (Asia Afrika) - JI Banceuy - JI ABC JI Naripan - Jl Sunda - Jl Veteran - Jl Ahmad Yani - Jl Gatot Subroto - Jl Burangrang - Jl Halimun - Jl Malabar - J Talaga Bodas - Jl Pelajar Pejuang - J Madanegara - Jl Reog - Jl Karawitan - JI Kliningan - Jl Buah Batu - Jl SukarnoHatta - Margahayu Raya - Metro - Riung Bandung - Pasar Induk GedeBage. Berikut peta trayek angkutan umum yang melayani sarana pendidikan Sekolah Dasar (SD/MI) di Kecamatan Batununggal.

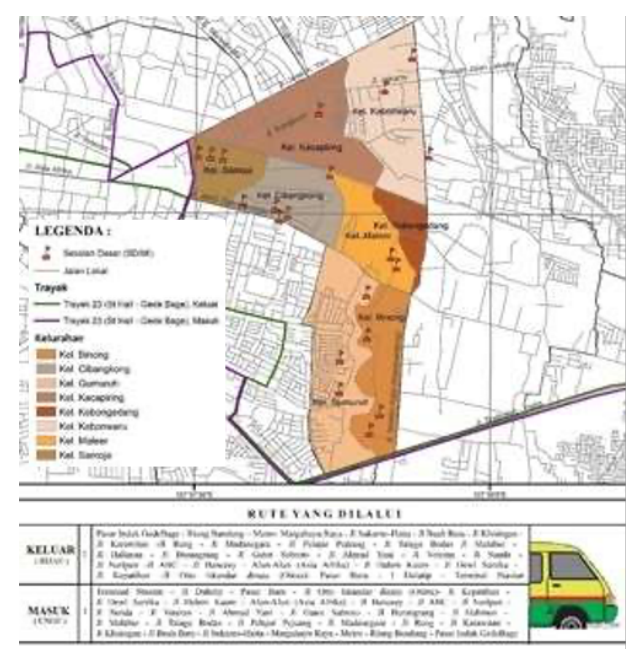

Gambar 10. Peta Trayek 23

\section{SIMPULAN}

Radius jangkauan pelayanan Sekolah Dasar (SD/MI) berdasarkan Peraturan Standar Nasional Indonesia (SNI) 03-1733-2004 yaitu $1000 \mathrm{~m}$, Kecamatan Batununggal sudah melayani setiap Kelurahannya, bahkan ketersediaan sarana pendidikan Sekolah Dasar (SD/MI) dapat menjangkau zona yang telah ditetapkan (zona c) yaitu Kecamatan Bandung Wetan, Kecamatan Lengkong, Kecamatan Kiaracondong, Kecamatan Bandung Kidul dan Kecamatan Regol. Aksesibilitas terdiri dari fasilitas pejalan kaki, fasilitas penyeberangan dan angkutan umum. Kondisi fasilitas pejalan kaki diketahui dari 20 Sekolah Dasar (SD/MI), hanya 3 sekolah yang tersedia pada fasilitas pejalan kaki berupa trotoar yaitu SDN 109 Centeh, SDN 203 Kacapiring dan SD Yayasan Beribu, 17 diantaranya tidak memiliki fasilitas pejalan kaki sehingga kondisi sekolahnya langsung ke badan jalan. Kondisi eksisting penyebrangan zebra cross hanya terdapat 3 sekolah yang menyebrang jalan raya yaitu SD Yayasan Beribu (Kelurahan Kebon Gedang) berada di Jalan BKR, SD Ignatius Slamet Riyadi (Kelurahan Cibangkong) berada di Jalan Gatot Subroto dan SD Alfa Centauri (Kelurahan Samoja) berada di Jalan Teratai. 17 sekolah diantaranya pada area permukiman dan tidak tersedia zebra cross. Trayek angkutan umum diketahui bahwa rute angkutan umum telah melayani semua zona pendidikan Sekolah Dasar (SD/MI) dengan 6 trayek yang tersedia di Kecamatan Batununggal, namun untuk zona 
sekolah yang berada di area permukiman, menjangkaunya harus berjalan kaki atau menggunakan kendaraan pribadi.

\section{REFERENSI}

Badan Standarisasi Nasional. (2004). SNI 031733-2004 tentang Tata cara perencanaan lingkungan perumahan di perkotaan. 58.

Doxiadis, C. A. (1970). Ekistics, the Science of Human Settlements: Ekistics starts with the premise that human settlements are susceptible of systematic investigation.Ekistics, the Science of Human Settlements: Ekistics starts with the premise that human settlements are susceptible of systematic investigation. Science, 170, 393-404.

Hadinoto, K. (1970). Unsur Pembentuk Kota.

Kecamatan Batununggal dalam Angka 2020. (2020). Bandung: Badan Pusat Statistik.

Peraturan Menteri Perhubungan Republik Indonesia Nomor 16 Tahun 2016 Tentang Penerapan Rute Aman Selamat Sekolah (RASS). (2016). Jakarta.

Peraturan Wali Kota Bandung Nomor 13 Tahun 2019 tentang Tata Cara Penerimaan Peserta Didik Baru pada Taman Kanakkanak, Sekolah Dasar, dan Sekolah Menengah Pertama. (2019). Bandung.

Simbolon, H. (2018, July 11). Zonasi PPDB Bermasalah, Orangtua Siswa di Bandung Kelimpungan .

Sujarto, D. (1992). Wawasan Tata Wawasan Tata Ruang, Wawasan mengenai Tata Ruang dan Pembangunan. Jurnal PWK.

Undang- Undang Republik Indonesia Nomor 20 Tahun 2003 pasal 12 ayat 1 tentang Sistem Pendidikan Nasional . (2003). 